\title{
The Internal Audit Performance: The Effectiveness of ERM and IT Environments
}

\author{
Wen-Hsien Tsai \\ Dept of Business Administration \\ National Cenrtal University \\ Jhongli, Taoyuan, Taiwan \\ whtsai@mgt.ncu.edu.tw
}

\author{
Hui-Chiao Chen \\ Dept of Accounting \\ National Yunlin University \\ of Science and Technology \\ Douliou, Yunlin, Taiwan \\ chenhch@yuntech.edu.tw
}

\author{
Jui-Chu Chang \\ Dept of Business Administration \\ National Cenrtal University \\ Jhongli, Taoyuan,Taiwan \\ jessiectw@gmail.com
}

\author{
Hsiu-Li Lee \\ Dept of Accounting Information \\ Chihlee University of Technology \\ Banciao, New Taipei, Taiwan \\ lee05301@mail.chihlee.edu.tw
}

\begin{abstract}
The purpose of this study is to examine the factors determining the performance of the internal audit (IA) in the context of internal auditors' work environments. This includes Enterprise Risk Management (ERM) implementation, the Enterprise Resource Planning (ERP) system, the use of auditing software and the internal auditors' IT (information technology) competence. Although a number of recent studies have reported tremendous changes in the roles of the IA, there is still little research on the influential factors of IA implementation and its effectiveness from a contextual perspective. This paper develops and tests a theoretical framework with samples from Taiwan. Data were analyzed using the structural equation model (SEM). This research confirms that the complete ERM implementation and effectiveness of ERP implementation have significant impacts on the performance of IA. It also highlights the importance of internal auditors' IT competence in improving the performance of IA.
\end{abstract}

\section{Introduction}

In the aftermath of several recent accounting scandals, internal audit (IA) has received increasing attention in regard to its ability to contribute towards corporate governance processes, including promoting effective controls, risk management and mitigating fraud risk [12]. Also in Taiwan, internal control and audit have received considerable attention:

"Premier Lin Chuan yesterday instructed the Financial Supervisory Commission (FSC) to form an investigative committee from members of the central bank, and the ministries of justice and finance after the New York branch of Mega International Commercial
Bank was ordered to pay a massive fine for violating US money-laundering rules. ... In light of the unprecedented severity of the issue, the Ministry of Finance said that it is to meet with the nation's eight state-controlled banks this week to assess and improve their internal controls and regulatory compliance." (Mon, Aug 22, 2016) [5]

According to the framework of corporate government proposed by the Institute of Internal Auditors (IIA), an effective IA is one of the four cornerstones of corporate governance, along with the audit committee of the board of directors, executive management and the external auditor [18].

Over the past several years, Enterprise Risk Management (ERM) has become an important approach in managing a wide array of risks in an integrated, enterprise-wide fashion [14]. It is known that the greater the extent of ERM implementation, the more efforts may be dedicated to the IA. More recently, Laura, Jenny and Nava [7] examined the relationship between internal auditors' involvement in ERM and the perceptions of their willingness to report to the audit committee. However, the use of ERM and its exact role in the performance of IA definitely merit more attention.

Previous research shows that information technology (IT) plays an important role in capturing and evaluating accounting information [9]. Since the Enterprise Resource Planning (ERP) system and auditing software were introduced, they have rapidly improved the quality of accounting and financial processes, changing auditing procedures, and improving coordination efficiency as well as the integration of various functional areas.

However, little research attention has been focused on these issues, especially in Taiwan. Moreover, internal auditors' expertise and IT capability (e.g., ERP system and auditing software) 
are usually regarded as beneficial for risk control, maintenance costs and auditing work; these may, in turn, impact the performance of IA. The extent to which internal auditors' IT competence influences the performance of IA still needs to be clarified.

This study aims to explore the status of ERM and ERP system implementation, usage of auditing software, internal auditors' competence in IT throughout Taiwanese firms, and how these contextual factors contribute to the performance of IA.

\section{Methodology}

In research literature, the IA has long been considered as a critical component of corporate governance as it plays an important monitoring role [2]. This study attempts to establish the connection between the performance of IA and its contextual factors, so that internal auditors may gain useful insights into the critical elements as they relate to IA performance, and provide guidance to bring the IA into full play and add strategic value to the company.

\subsection{Hypotheses development}

Companies with IA functions or departments are usually significantly larger, more highly regulated, more competitive and more profitable. There are many factor-based studies explaining the factors that may affect the performance of IA.

2.1.1. The extent of ERM implementation. According to the framework developed by the Committee of Sponsoring Organizations of the Treadway Commission (COSO), ERM is defined as “a process, affected by an entity's board of directors, management, and other personnel, applied in strategy setting and across the enterprise, designed to identify potential events that may affect the entity, and manage risks to be within its achievement of entity objectives" [6]. ERM needs IA to evaluate how potential events might affect the achievement of a company's objectives. IA plays a variety of core roles in their company's ERM activities. Thus, the ERM process begins by defining the audit areas. A recent IIA Research Foundation study indicated that the reason IA departments are not involved in ERM activities may be due to the poor awareness of ERM and its implementation process [11]. In addition, modern IA requires effective, efficient and economic audit planning as a means to achieve audit objectives, such as appropriate risk and control coverage, as well as effective risk assessment [21]. Thus, the greater the extent of ERM implementation, the more critical the role that the IA may play and the more effort may be dedicated to IA implementation to ensure the appropriate implementation of ERM activities, and in turn, the more effective the IA becomes. It is reasonable to expect:

\section{H1. The extent of ERM implementation is positively related to the performance of IA.}

2.1.2. The Effectiveness of the ERP System. The major reason for ERP implementation is always business process improvement [26]. Given that ERP systems can automate business processes and enable process changes at the operational level, they have the potential to reduce the cost and cycle time, as well as improve productivity, quality and customer satisfaction [28]. The ERP systems also offer benefits supporting decision-making [13]. Organizations with successful ERP systems should realize and experience substantial tangible and intangible improvements in regard to six criteria: (1) System quality, (2) Information quality, (3) Use of the ERP system, (4) User satisfaction, (5) Individual impact, and (6) Organizational impact [3, 8, 29]. Effective ERP systems allow companies to improve the quality of accounting and financial information, as well as the performance of individual internal auditors (e.g., performance, individual productivity, decision quality, information awareness, inventory, etc.), which in turn, benefit the performance of the IA. In short, the better the effectiveness of the ERP system, the better the performance of the IA. Hence, it can be hypothesized:

\section{H2. The effectiveness of an ERP system is positively related to the performance of IA.}

2.1.3. The use of auditing software. Based on the fact that IT can increase the quality and productivity of IA by means of audit automation, eliminating certain audit procedures, and enhancing information and knowledge-sharing capabilities [23, 31], internal auditors have been expected to use computer-assisted audit techniques (CAATs, i.e. auditing software) to evaluate risks of fraud [1], identify journal entries and other adjustments to be tested [1, 19, 22], and assist them in auditing information systems (e. g., ERP system) [15]. Besides, recent audit standards also suggest that internal auditors should consider using generalized auditing software and advanced techniques, such as testing data produced and integrating test facilities [17]. As indicated by Dowling and Leech [10], internal auditors must use IA support software appropriately; otherwise, the quality of accounting and financial statements may be 
damaged, and worse still, it can have a negative impact on stakeholders who use this information to make decisions. Therefore, a positive relationship is expected between the use of auditing software and the performance of IA. It is proposed:

\section{H3. The use of auditing software is positively related to the performance of IA.}

2.1.4. The internal auditors' competence in using IT. Although the ERP systems and auditing software may be considered beneficial for IA work, internal auditors may still feel it is difficult and complicated to use these systems owing to their lack of sufficient knowledge or unfamiliarity with these new technologies [4, 22]. As a result, the ERP system or auditing software may be unable to benefit their work and the performance of IA. On the other hand, the internal auditors should use their competence in IT to evaluate and monitor organizational risk, controls and compliance, especially those that may be caused by IT implementation [32]. During the entire information system's implementation period, internal auditors are able to accumulate their IT expertise, experience and transfer knowledge within their organizations [16], which in turn, make the ERP system or auditing software easier to use and contributes to the performance of IA. Thus, this paper proposes that the greater the IT competence internal auditors have, the more effective the IA becomes. Based on the discussion, it can be hypothesized:

\section{H4. The internal auditors' competence in using IT is positively related to the performances of IA.}

In summary, it is expected that increased ERM implementation, effective ERP systems, appropriately used auditing software and high competence in IT can lead to better IA. However, on account of internal auditors' critical role in IA performance, another factor is also considered, their professional capability in IA because this may also affect the IA's performance. The research model is presented in Figure 1.

\subsection{Measures}

To test the hypotheses, a self-administered survey was used to collect data. A questionnaire was designed to capture the respondents' perceptions and experiences concerning the research variables; the respondents were internal audit managers in Taiwanese firms.

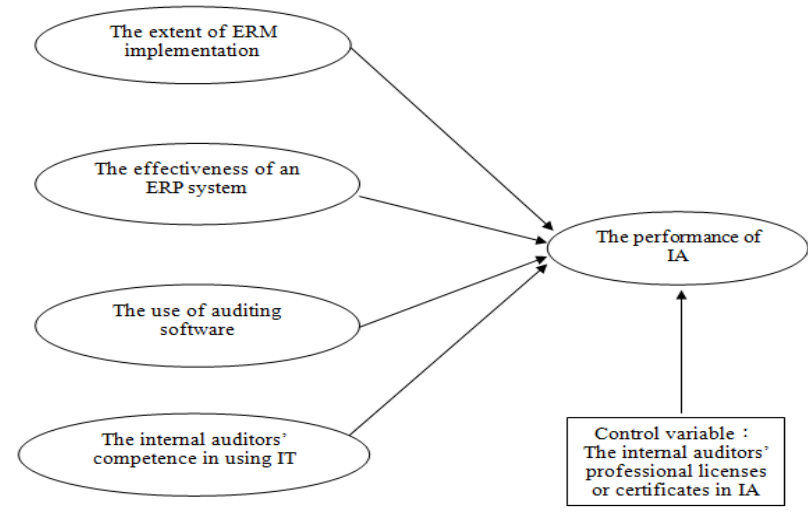

Figure 1. Research model

*The full names and codes of variables and their measures are shown in Table 1

The extent of ERM implementation (ERM_EXT) was measured by the status of the eight ERM activities, respectively: internal environment, object setting, event identification, risk assessment, risk response, control activities, information/ communication and monitoring [6].

The effectiveness of the ERP system (ERP_EFF) was defined with only four of six criteria because of the consideration of parsimony and their potential impact on internal auditors' jobs: (1) the system quality, (2) the information quality, (3) user satisfaction and (4) individual impact, which have been mentioned previously [8, 27, 29].

There are numerous definitions of competence in many different areas of research. The competence of IT can be conceptually divided into three dimensions: IT competence, business competence and transdisciplinary competence [20]. However, in this study, competence is considered as the potential that leads to an effective use of IT. Thus, for simplicity, only IT competence was investigated: the capability that enables internal auditors to effectively apply IT in their jobs. The internal auditor's IT competence was assessed by their (1) technology knowledge (IT_TK), (2) conceptual knowledge (IT_CK) and (3) realization competence (IT_RC) in regard to IT. A dummy variable was used in the measurement model. The use of auditing software (IAS_USE) was measured by a dummy variable where $0=$ No and $1=$ Yes.

The performance of IA (IA_PFM) can be classified into two dimensions: one is the performance of the IA department (IA_DPFM) and the other is the IA's contribution to its company (IA_CPFM). The former is measured by five criteria [24]: (1) output: the end-result or products of the internal function, (2) quality: the quality of the auditing process, end result, and auditing staff, (3) 
efficiency: the efficiency of using auditing time and resources versus its costs, (4) impact: the achievement of department goals and contribution to the ERM, and (5) environment: the improvement of organizational communication and trust among various stakeholders. The latter is measured by seven criteria [25]: (1) achieve the company's annual goals, (2) explore the opportunity of improving business processes, (3) improve the quality of internal control and reduce the potential damage to shareholder confidence, (4) provide message feedback and prevent surprises, (5) perform financial and nonfinancial certification programs, (6) improve organizational control and operational performance, and (7) enhance public image and reputation. In addition to these latent independent constructs, it was also considered whether the internal auditors have any professional license or certificate in IA as a control variable (IA_PROF) measured by a dummy variable where $0=$ No and $1=$ Yes.

\subsection{Data collection and analysis}

This study draws on the convenient sample from the 2011 annual meeting held by the Institute of Internal Auditors, Taiwan. A total of 680 questionnaires were sent to internal auditors. A total of 253 responses were received for an effective response rate of $37.21 \%$. Of these, 41 responses were rejected before processing because they did not have IA departments, were missing responses or had unusable ones. Therefore, the final investigative samples included 212 completed questionnaires.

The measure validation and model testing were conducted using structural equation model (SEM). First, exploratory factor analyses (EFA) and reliability analyses were conducted to analyze items separately for each facet. Based on the results (see Table 1), EFA yielded a three-factor solution for the status of ERM implementation (ERM_EXT) that accounted for $86.076 \%$ of the variance extracted, namely internal risk management (ERM_IRM, $\alpha=0.925$ ), risk evaluation management (ERM_REM, $\alpha=0.974)$ and supervisory environment management (ERM_SEM, $\alpha=0.960$ ). EFA also yielded a threefactor solution for the effectiveness of the ERP system that accounted for $88.856 \%$ of the variance extracted, namely ERP system/information quality (ERP_SIQ, $\alpha=0.963$ ), ERP impact on individuals (ERP_IMP, $\alpha=0.974)$ and ERP satisfaction (ERM_SAT, $\alpha=0.977)$. The 16 items for ERM_EXT and $1 \overline{6}$ items for ERP_EFF were retained because they demonstrated acceptable loading on their hypothesized factor (>.5) and no significant crossloading for further analysis.
For the internal auditors' competence in using IT (IT_CPT), EFA yielded a three-factor solution that accounted for $77.393 \%$ of the variance extracted, corresponding closely with the hypothesized dimensions of IT competence, i.e. IT_TK $(\alpha=0.884)$, IT_CK $(\alpha=0.872)$ and IT_RC $(\alpha=0.838)$. The result showed that 5 of 15 items were dropped. Likewise, EFA also yielded a two-factor solution for the performance of IA (i.e., IA_DPFM $(\alpha=0.946)$ and IA_CPFM $(\alpha=0.944))$ that accounted for $82.131 \%$ of the variance extracted, corresponding closely with the hypothesized dimensions. The result revealed that 10 of 12 items were retained.

Second, a subsequent confirmatory factor analysis was conducted (CFA) to purify the measures. In the measurement model the constructs in our hypotheses represent a second-order factor (e.g., ERM_EXT, ERP_EFF, IT_CPT and IA_PFM), with the observed items representing first-order factors, which in turn represent a second-order factor. Average scores were used among retained items to reflect each of the firstorder constructs (e.g., ERM_IRM, ERM_REM, etc), with error variance fixed at a level appropriate to its coefficient alpha reliability.

For the single-item constructs, i.e., IAS_USE and IA_PROF, the item loading was set to 1.0 and error term to 0.0 . This measurement model produced the following fit statistics: CMIN $=36.706(\mathrm{p}=0.919)$, degrees of freedom (d.f.) $=50, \mathrm{GFI}=0.974, \mathrm{AGFI}=$ $0.953, \mathrm{CFI}=1.000, \mathrm{NFI}=0.972, \mathrm{RMSEA}=0.000$, $\mathrm{PCFI}=0.641$ and $\mathrm{x} 2 / \mathrm{df}=0.734$. Overall, the model provides a reasonable fit for the data. All items loaded significantly on their designated first-order constructs, with no evidence of any cross-loading.

\section{Results}

As shown in Figure 2, the result of path analysis significantly confirms most hypotheses. The predictive capability of this model is acceptable; the explained variance or the R2 is 0.703 for the endogenous constructs of the performance of IA (IA_PFM). The result implies that this model explains $70.3 \%$ of IA_PFM. As indicated by the path coefficient, the extent of ERM implementation (ERM_EXT, $\quad \beta=0.362, \quad \mathrm{p}<0.01$ ) is positively associated with IA_PFM. Thus, hypothesis 1 is supported; this implies that the greater extent of ERM implementation can lead to higher IA_PFM.

The implementation of the ERP system (specifically, its integration in regard to the functional and organizational scope that have been reached) can facilitate improvements in the role of management accountants, including the elimination 
of routine jobs, line managers with more accounting knowledge, more forward-looking information and a wider role for management accountants. This finding suggests that internal audit, as an important function in management accounting, also can benefit from the implementation of the ERP system. Previous studies on the implementation of ERP systems mainly focused on the contribution of ERP to organizational performance [30]. However, due to ERP's broad functionality and integration, a company not only can achieve a tremendous improvement in organizational performance but also can typically replace their legacy system for internal audit, automate internal audit processes, and improve the quality of accounting and financial processes with ERP applications.

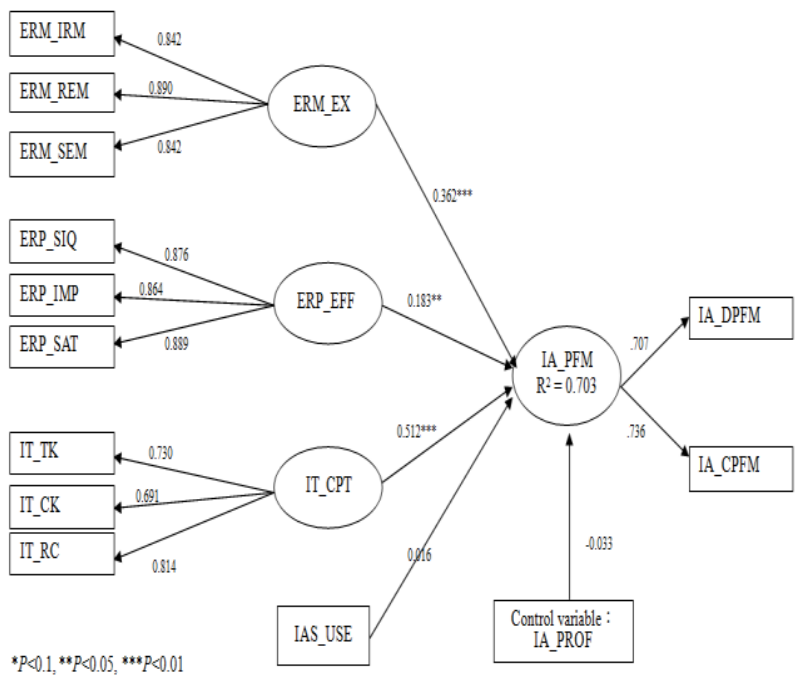

Fig. 2. Result of the path analysis

*The full names of variables and their measures are shown in Table 1.

As expected, the findings in this paper show that the effectiveness of the ERP system (ERP_EFF, $\beta=0.183, p<0.05)$ is found to have positive impacts on IA_PFM. Thus, hypothesis 2 is supported. These results provide evidence that a successful ERP system (i.e., the ERP system perceived to be effective by internal auditors) is significantly beneficial for IA_PFM due to better IS success factors, such as the quality of the information and system (ERP_SIQ), user satisfaction (ERP_SAT) and the individual productivity of internal auditors (ERP_IMP). As mentioned earlier, the greater the effectiveness of the ERP system, the more precise and accurate the accounting/financial information, and thus the greater the improvement in IA_PFM. The results in this paper confirm this conclusion.
However, the use of auditing software (IAS_USE) is not found to be significantly relevant to IA_PFM. Hypothesis 3 is not supported. One could tentatively surmise that more than $50 \%$ of the participants $(59.3 \%)$ were using the auditing software. Thus, even though the IAS_USE may lead to better IA_PFM, there does not appear to be a meaningful difference in IA_PFM because most participants were already using the audit software, so Hypothesis 3 is therefore not supported.

This paper's findings also show that the internal auditors' competence in using IT (IT_CPT) can raise the level of IA_PFM. Hypothesis 4 is supported. This means that IT_CPT strengthens the effectiveness of IA_PFM through the IT expertise and experience of internal auditors, which can enhance audit quality and productivity in areas such as audit automation, quality and efficiency of auditing process, and the effectiveness of the audit system. This finding also confirms the studies of Manson et al. [23] and VeraMuñoz et al. [31]. They argued that IT appears to increase audit quality and productivity through audit automation, eliminating certain audit procedures, and enhancing information and knowledge-sharing capabilities. Therefore, it is believed that the effectiveness of both the ERP system and the internal auditors' IT competence plays an important role in enhancing IA_PFM.

As for the control variable, the internal auditors' professional licenses or certificates (IA_PROF), it is not significantly related to IA_PFM. This indicates that IA_PROF does not affect IA_PFM. One reason may be that most participants $(53.3 \%)$ already have professional licenses or certificates in IA. In contrast to the other independent variables, the impact of IA_PROF on IA_PFM is limited.

In summary, the results of this study highlight the importance of complete ERM implementation, effective ERP system and sufficient IT competence of internal auditors in the performance of IA. In decreasing order of importance, IT_CPT, ERM_EXT and ERP_EFF were the factors that had the most impact on the performance of IA.

\section{A lesson learned}

Based on the results, it is proposed that the performance of internal audit can be improved through complete ERM implementation, an effective ERP system and sufficient competence of the internal auditors' IT skill. In addition, these results also show that investments in the internal auditors' work environment, i.e., ERM, ERP system and IT competence, are worthwhile due to their tremendous effect on the performance of internal audit. 


\section{Conclusion}

The results of this study can contribute to the knowledge concerning the factors influencing the superior performance of IA. The empirical results confirm most of the research hypotheses $(\mathrm{H} 1, \mathrm{H} 2$ and H3) regarding the presence of certain internal auditors' work environment factors (i.e., complete ERM implementation, effective ERP system and personal competence in IT) that explain the performance of IA.

The results in this paper demonstrate that the internal control environment (i.e., the complete ERM implementation and effective ERP system) and internal auditors' IT competence are positively related to IA_PFM. As indicated by the larger parameter estimates, the IT_CPT and the ERM_EXT both have strong effects on IA_PFM. This result suggests that the companies need to enhance their internal auditors' IT_CPT and implement ERM completely to improve the IA_PFM. In addition, a satisfactory ERP system also can lead to greater IA_PFM. These results suggest that the computeraided environment constituted by the ERP system and IT competence can help to improve IA.

Based on the research of the ERM, ERP system and internal audit, this paper developed and tested an IA's performance model under the internal auditors' work environment context. The results largely support the hypothesized relationships in this research model. This research confirms that the complete ERM implementation and effectiveness of ERP implementation have significant impacts on the performance of IA. It also highlights the importance of internal auditors' IT competence in improving the performance of IA. Organizations should properly employ these critical components to enhance the effectiveness of internal audit.

As with any study, there are limitations in the present work that need to be identified. First, the limitations mainly refer to the focus of the analysis on the impact of internal auditors' work environment factors. In future research, other factors of influence, such as different types of ERP systems (e.g., Data System, Oracle, SAP, etc.), auditing software and investment costs with respect to IT, should be included in the research model. Second, the available measures are all self-reported by internal auditors and thus subject to bias. Future research should obtain more objective measures to evaluate the ERM_EXT, ERM_EFF, IT_CPT, IAS_USE and IA_PFM. Third, even though the internal auditors' work environments were considered in this study, the roles played by other organizational and environmental factors, such as corporate governance, complexity, formalization, strategy or industry competition were still excluded. Therefore, future research should investigate their roles and impact on IA_PFM.

\section{Acknowledgement}

We would like to thank the National Science Council of Taiwan for financially supporting this research under Grant No. MOST103-2410-H008036-MY3.

\section{References}

[1] American Institute of Certified Public Accountants (AICPA), Consideration of Fraud in Financial Statement Audit. Statement of Auditing Standards No.99 (2002), New York, NY: AICPA.

[2] D. Anderson, J. R. Francis, and D. J. Stokes, Auditing, directorships, and the demand for monitoring, Journal of Accounting and Public Policy 12 (4) (1993) 353375.

[3] E. W. N. Bernroider, IT governance for enterprise resource planning supported by the DeLone-McLean model of information systems success, Information \& Management 45 (5) (2008) 257-269.

[4] S. I. Chang, C. C. Wu, and I.C. Chang, The Development of a Computer Auditing System Sufficient for Sarbanes-Oxley Section 404- A Study on the Purchasing and Expenditure Cycle of the ERP System, Information Systems Management 25(3) (2008) 211-229.

[5] T. Chen, FSC commission to probe Mega Bank. Taipei Time (Aug 22, 2016). Available at: http://www.taipeitimes.com/News/front/archives/201 6/08/22/2003653605

[6] Committee of Sponsoring Organizations of the Treadway Commission, Enterprise risk managementintegrated framework executive summary 2004. Available at: http://www.coso.org/Publications/ERM/COSO_ERM _ExecutiveSummary.pdf.

[7] de Zwaan, L., S. Jenny, and N. Subramaniam, Internal audit involvement in enterprise risk management. Managerial Auditing Journal 26(7) (2011) 586-604.

[8] W. DeLone and E. McLean, The DeLone and McLean model of information system success: a ten year update, Journal of Management Information Systems 19 (4) (2003) 9-30.

[9] C. Dowling, Appropriate Audit Support System Use: The Influence of Auditor, Audit Team, and Firm Factors, The Accounting Review 84(3) (2009) 771810. 
[10] C. Dowling and S.A. Leech, Audit support systems and decision aids: Current practice and opportunities for future research, International Journal of Accounting Information Systems 8(2) (2007) 92-116.

[11] A. A. Gramling and P. M. Myers, Internal auditing's role in ERM. (cover story), Internal Auditor63(2) (2006) 52-58.

[12] D. R. Hermanson, D. M. Ivancevich, and S. H. Ivancevich, Building an Effective Internal Audit Function: Learning from SOX Section 404 Reports, Review of Business 28(2) (2008) 13-28.

[13] C. W. Holsapple and M. P. Sena, ERP plans and decision-support benefits. Decision Support Systems 38(4) (2005)575-590.

[14] R. E. Hoyt and A. P. Liebenberg, The Value of Enterprise Risk Management. Journal Of Risk \& Insurance 78(4) (2011) 795-822.

[15] S. M. Huang, D. C. Yen, Y. C. Hung, Y. J. Zhou, and J. S. Hua, A business process gap detecting mechanism between information system process flow and internal control flow. Decision Support Systems 47(4) (2009) 436-454.

[16] W. H. Hung, C. Ho, J. Jou, and K. Kung, Relationship bonding for a better knowledge transfer climate: An ERP implementation research. Decision Support Systems 52(2) (2012) 406-414.

[17] Information System Audit and Control Association (ISACA), CISA Review Manual. Illinois: Information System Audit and Control Association 2003.

[18] Institute of Internal Auditors (IIA), Corporate governance. The Institute of Internal Auditors Homepage (2005). Available at: http: / /www.theiia.org/?doc id1041.

[19] D. Janvrin, J. Bierstaker, and D. J. Lowe, An Investigation of Factors Influencing the Use of Computer-Related Audit Procedures, Journal of Information Systems 23(1) (2009) 97-118.

[20] T. Kollmann, M. Häsel, and N. Breugst, Competence of IT Professionals in E-Business Venture Teams: The Effect of Experience and Expertise on Preference Structure. Journal of Management Information Systems 25(4) (2009) 51-79.

[21] A. Koutoupis and A. Tsamis, Risk based internal auditing within Greek banks: a case study approach. Journal of Management \& Governance 13(1/2) (2009) 101-130.

[22] R. B. Lanza and S. Gilbert, A risk-based approach to journal entry testing, Journal of Accountancy 204 (July) (2007) 32-35.

[23] S. Manson, S. McCartney, M. Sherer, and W. A. Wallace, Audit automation in the U.K. and the U.S.: A comparative study, International Journal of Auditing, 2 (November) (1998) 233-246.

[24] D. S. B. Soh, and N. Martinov-Bennie, The internal audit function perceptions of internal audit roles, effectiveness and evaluation, Managerial Auditing Journal 26(7) (2011) 605-622.

[25] R. F. Spekl'e, H. J. van Elten, and A.M. Kruis, Sourcing of internal auditing: An empirical study, Management Accounting Research 18 (2007)102-124.

[26] W. H. Tsai, Y. W. Fan, J. D. Leu, L. W. Chou, and C. C. Yang, The Relationship between Implementation Variables and Performance Improvement of ERP Systems, International Journal of Technology Management 38(2) (2007) 350-373.

[27] W. H. Tsai, K. C. Lee, J. Y. Liu, S. J. Lin, and Y. W. Chou, The Influence of Enterprise Resource Planning (ERP) Systems' Performance on Earnings Management, Enterprise Information Systems 6(4) (2012) 491-517.

[28] W. H. Tsai, P. L. Lee, Y. S. Shen, and H. L. Lin, A Comprehensive Study of the Relationship between Enterprise Resource Planning Selection Criteria and Enterprise Resource Planning System Success, Information \& Management 49(1) (2012) 36-46.

[29] W. H. Tsai, M. J. Shaw, Y. M. Fan, J. Y. Liu, K. C. Lee, and H. C. Chen, An Empirical Investigation of the Impacts of Internal/External Facilitators on the Project Success of ERP: A Structural Equation Model, Decision Support Systems 50(2) (2011) 480-490.

[30] S. Uwizeyemungu and L. Raymond, Linking the Effects of ERP to Organizational Performance: Development and Initial Validation of an Evaluation Method. Information Systems Management 27(1) (2010) 25-41.

[31] S. C. Vera-Muñoz, J. L. Ho, and C. W. Chow, Enhancing knowledge sharing in public accounting firms, Accounting Horizons 20 (2) (2006) 133-155.

[32] M. L. Weidenmier and S. Ramamoorti, Research Opportunities in Information Technology and Internal Auditing, Journal of Information Systems 20 (1) (2006)

205-213. 
Table 1 Result of factor analysis

\begin{tabular}{|c|c|c|c|}
\hline & $\begin{array}{l}\text { Factor } \\
\text { Loading }\end{array}$ & $\begin{array}{l}\text { Cronbach } \\
\alpha\end{array}$ & $\begin{array}{l}\text { Total(\%) } \\
\text { Variance } \\
\text { Explained }\end{array}$ \\
\hline $\begin{array}{l}\text { The extent of ERP implementation (ERM EXT) } \\
\text { 1) risk evaluation management (ERP REM) }\end{array}$ & & 0.974 & 86.076 \\
\hline $\begin{array}{l}\text { a. capability to design proper action plans to deal } \\
\text { with risks }\end{array}$ & 0.869 & & \\
\hline b. capability to deal with the impacts of the risks & 0.825 & & \\
\hline c. having adequate action plans to deal with risks & 0.817 & & \\
\hline $\begin{array}{l}\text { d. capability to ensure the risks are appropriately } \\
\text { managed }\end{array}$ & 0.803 & & \\
\hline $\begin{array}{l}\text { e. capability to evaluate the impacts of the risks } \\
\text { rigorously }\end{array}$ & 0.794 & & \\
\hline $\begin{array}{l}\text { f. capability to evaluate the possibilities of the risks } \\
\text { rigorously }\end{array}$ & 0.793 & & \\
\hline g. having rigorous assessment of each risk's impact & 0.706 & & \\
\hline $\begin{array}{l}\text { h. having rigorous assessment of each risk's } \\
\text { possibility }\end{array}$ & 0.705 & & \\
\hline 2) supervisory environment management (ERM_SEM) & & 0.960 & \\
\hline $\begin{array}{l}\text { a. having period evaluation of the control and } \\
\text { reporting system for each activity }\end{array}$ & 0.887 & & \\
\hline $\begin{array}{l}\text { b. having period control and reporting about internal } \\
\text { control defects }\end{array}$ & 0.854 & & \\
\hline $\begin{array}{l}\text { c. having effective control and reporting system for } \\
\text { each risk }\end{array}$ & 0.821 & & \\
\hline $\begin{array}{l}\text { d. having effective and comprehensive control of each } \\
\text { activity }\end{array}$ & 0.707 & & \\
\hline 3) internal risk management (ERP_IRM) & & 0.925 & \\
\hline a. the concept of management & 0.816 & & \\
\hline $\begin{array}{l}\text { b. the board of directors' integrity and moral } \\
\text { philosophy }\end{array}$ & 0.804 & & \\
\hline c. the board of directors' attitude toward risks & 0.797 & & \\
\hline d. the employees' attitude toward risks & 0.652 & & \\
\hline The effectiveness of the ERP system (ERP_EFF) & & & 88.856 \\
\hline 1) the system and information quality (ERP_SIQ) & & 0.963 & \\
\hline a. Data currency & 0.808 & & \\
\hline b. Database content & 0.799 & & \\
\hline c. System accuracy & 0.795 & & \\
\hline d. Data accuracy & 0.786 & & \\
\hline e. Timeliness of information provision & 0.765 & & \\
\hline f. Relevance of information & 0.762 & & \\
\hline 2) individual impact (ERP_IMP) & & 0.974 & \\
\hline a. Individual productivity & 0.831 & & \\
\hline b. Information awareness & 0.827 & & \\
\hline c. Decision quality & 0.824 & & \\
\hline d. Job performance & 0.809 & & \\
\hline e. Accurate interpretation & 0.804 & & \\
\hline 3) user satisfaction (ERP_SAT) & & 0.977 & \\
\hline a. System interface satisfaction & 0.831 & & \\
\hline b. Overall satisfaction & 0.816 & & \\
\hline c. Software satisfaction & 0.814 & & \\
\hline d. The ERP project satisfaction & 0.781 & & \\
\hline e. Information satisfaction & 0.771 & & \\
\hline
\end{tabular}


Table 1 Result of factor analysis (Continued)

\begin{tabular}{|c|c|c|c|}
\hline \multicolumn{2}{|l|}{ The internal auditors' IT competence (IT_CPT) } & \multirow{6}{*}{0.884} & \multirow[t]{14}{*}{77.393} \\
\hline 1) technology knowledge (IT_TK) & & & \\
\hline $\begin{array}{l}\text { a. knowledge of data protection, security and } \\
\text { recovering }\end{array}$ & 0.845 & & \\
\hline b. capability to use internal auditing software & 0.806 & & \\
\hline $\begin{array}{l}\text { c. Knowledge and technical ability of data access and } \\
\text { data security }\end{array}$ & 0.775 & & \\
\hline $\begin{array}{l}\text { d. Knowledge and ability of computer-aided internal } \\
\text { control process }\end{array}$ & 0.764 & & \\
\hline 2) conceptual knowledge (IT_CK) & & 0.872 & \\
\hline a. knowledge of inquiry on the Internet and its security & 0.879 & & \\
\hline b. capability to learn new software and applications & 0.823 & & \\
\hline c. knowledge of computer virus and defense & 0.771 & & \\
\hline 3) realization competence (IT_RC) & & 0.838 & \\
\hline a. capability to use working software (e.g., ATB, etc.) & 0.875 & & \\
\hline $\begin{array}{l}\text { b. capability to use auditing software and } \\
\text { computer-aided tools(e.g., ACL, IDEA, etc.) }\end{array}$ & 0.845 & & \\
\hline $\begin{array}{l}\text { c. capability to use database management software } \\
\text { (e.g., Access, SQL, etc.) }\end{array}$ & 0.712 & & \\
\hline \multicolumn{2}{|l|}{ The performance of internal audit (IA_PFM) } & 0.946 & 82.131 \\
\hline \multicolumn{4}{|l|}{ 1) The performance of IA department (IA_DPFM) } \\
\hline a. the achievement of department goals & 0.911 & & \\
\hline $\begin{array}{l}\text { b. the improvement of organizational } \\
\text { communication and trust development among } \\
\text { various stakeholders }\end{array}$ & 0.885 & & \\
\hline $\begin{array}{l}\text { c. assurance audits, auditing process and advisory } \\
\text { services }\end{array}$ & 0.880 & & \\
\hline $\begin{array}{l}\text { d. the quality of the auditing process, end result, and } \\
\text { auditing staff }\end{array}$ & 0.874 & & \\
\hline $\begin{array}{l}\text { e. the efficiency of using auditing time and } \\
\text { resources versus its costs }\end{array}$ & 0.819 & & \\
\hline 2) IA's contribution to its company (IA_CPFM) & & 0.944 & \\
\hline $\begin{array}{l}\text { a. improve organizational control and operational } \\
\text { performance }\end{array}$ & 0.891 & & \\
\hline $\begin{array}{l}\text { b. explore the opportunity of improving business } \\
\text { processes }\end{array}$ & 0.886 & & \\
\hline $\begin{array}{l}\text { c. improve the quality of internal control, and reduce } \\
\text { the potential damage to shareholder confidence }\end{array}$ & 0.869 & & \\
\hline d. provide message feedback and prevent surprises & 0.861 & & \\
\hline $\begin{array}{l}\text { e.perform financial and non-financial certification } \\
\text { programs }\end{array}$ & 0.852 & & \\
\hline
\end{tabular}

